\title{
Tobacco, alcohol and use of other recreational drugs within HIV-infected treated cohorts: the leDEA West Africa collaboration
}

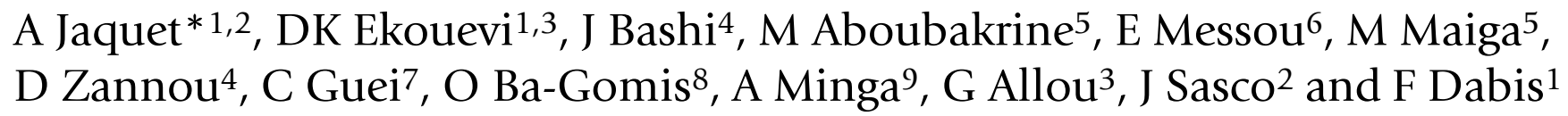

Address: ${ }^{1}$ HIV Epidemiology, INSERM CRE U 897, ISPED, Université Victor Segalen, Bordeaux, France, ${ }^{2}$ Epidemiology for Cancer, INSERM CRE U 897, ISPED, Université Victor Segalen, Bordeaux, France, ${ }^{3}$ IeDEA West Africa Regional Office, PACCI, CHU Treichville, Abidjan, Côte d'Ivoire, ${ }^{4} \mathrm{CNHU}$ University Hospital, Cotonou, Benin, ${ }^{5} \mathrm{Gabriel}$ Touré University Hospital, Bamako, Mali, ${ }^{6}$ ACONDA-CePReF, Adultes, Abidjan Côte d'Ivoire, 7 Unité de Soins Ambulatoires et de Conseil (USAC), Abidjan, Côte d'Ivoire, ${ }^{8}$ Centre Intégré de Recherche Bioclinique d'Abidjan (CIRBA), Abidjan, Côte d'Ivoire and ${ }^{9}$ Centre National de Transfusion Sanguine d'Abidjan (CNTS), Abidjan, Côte d'Ivoire

* Corresponding author

from II th International Conference on Malignancies in AIDS and Other Acquired Immunodeficiencies (ICMAOI): Basic, Epidemiologic, and Clinical Research

Bethesda, MD, USA. 6-7 October 2008

Published: 17 June 2009

Infectious Agents and Cancer 2009, 4(Suppl 2):P24 doi:10.1 186/1750-9378-4-S2-P24

This abstract is available from: http://www.infectagentscancer.com/content/4/S2/P24

(c) 2009 Jaquet et al; licensee BioMed Central Ltd.

\section{Background}

Cardiovascular diseases and cancers are an emerging problem among HIV-infected persons once Highly Active Antiretroviral Therapy (HAART) is used for prolonged periods of time. Tobacco and alcohol consumption are well-known risk factors of many non-AIDS classifying cancers but are poorly documented in sub-Saharan Africa. We aimed to estimate the prevalence of cancer risk behaviors classifiable as addictions (tobacco, alcohol and recreational drugs) among HAART-treated HIV-infected patients in the West African region.

\section{Methods}

A cross-sectional survey was conducted in eight adult centers participating to the International epidemiological Database to Evaluate AIDS (IeDEA) in West Africa collaboration (five in Abidjan, Côte d'Ivoire, two in Bamako, Mali and one in Cotonou, Benin). During a 4-week period, especially trained health workers administered to HAART-treated patients a standardized and validated questionnaire assessing current and past smoking status, alcohol drinking and use of selected recreational drugs.

\section{Preliminary results}

From May 21 to June 6, 2008, 813 HIV-infected patients on HAART participated to the first phase of this study
(194 men and 619 women). In Côte d'Ivoire, 57.2 percent (95\% CI $+/-6.8 \%)$ of men reported a current or a past history of smoking and 23 percent $(95 \% \mathrm{CI}+/-5.8 \%)$ admitted being current smokers. Of the group, 43.1 percent (95\% CI +/- 7\%) declared current alcohol consumption during the last year and 56.7 percent $(95 \% \mathrm{CI}+/-6.9 \%)$ declared alcohol intake before this last year. In Ivoirian women, 5.3 percent $(95 \% \mathrm{CI}+/-1.7 \%)$ declared a current or a past history of smoking and 1.4 percent $(95 \% \mathrm{CI}+/$ $0.9 \%)$ admitted being current smokers. In Ivoirian women, 24.6 percent $(95 \% \mathrm{CI}+/-3.4 \%)$ declared current alcohol consumption during the last year and 37.0 percent $(95 \% \mathrm{CI}+/-3.8 \%)$ declared alcohol intake before this last year. In Mali, 81.1 percent (95\% CI +/-12.4\%) of men declared a current or past history of smoking, 48.6 percent (95\% CI +/- 16.1\%) being current smokers. Of the Mali men, 5.4 percent declared current alcohol consumption during the last year and 16 percent declared alcohol intake before this last year. In Malian women, 6.3 percent (95\% $\mathrm{CI}+/-4.6 \%$ ) declared a current or past history of smoking, with 2.7 percent being current smokers. In Malian women, 3.7 percent declared current alcohol consumption during the last year and 4.3 percent declared alcohol intake before this year. The full data set will comprise data on 1,400 HAART-treated patients in Côte d'Ivoire, 600 in 
Mali and 400 in Benin and will be correlated with sociodemographic, clinical and therapeutic characteristics.

\section{Discussion}

This information will help 1) at the patient level to provide targeted educational support to HAART-treated patients on these addictions; 2 ) at the population level to provide reliable estimates of the long-term impact of such consumptions on the prognosis of these African patients.

Publish with Bio Med Central and every scientist can read your work free of charge

"BioMed Central will be the most significant development for disseminating the results of biomedical research in our lifetime. " Sir Paul Nurse, Cancer Research UK

Your research papers will be:

- available free of charge to the entire biomedical community

- peer reviewed and published immediately upon acceptance

- cited in PubMed and archived on PubMed Central

- yours - you keep the copyright

Submit your manuscript here:

http://www.biomedcentral.com/info/publishing_adv.asp 